\title{
$(\mathfrak{G} \mathfrak{n} \mathfrak{n d} \mathfrak{b} \mathfrak{u c h} \mathfrak{o r d} \mathfrak{m} \mathfrak{n} \mathfrak{g}$

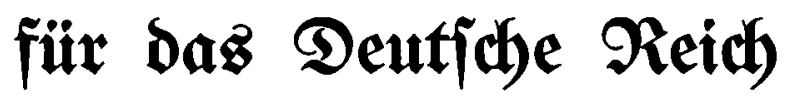

\author{
vom 24. Mlärz 1897
}

unter bejonberer Berücfijichtigung bez bayerijd)en Aluzfü̈hrungsz=

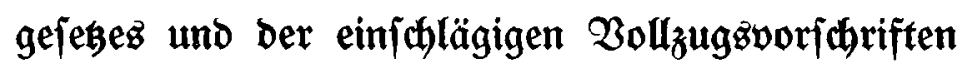

exläutert oon

\section{Georg Meifel,}

Rgl. Oberamtäridter in Niünфen.

2. neubearbeitete und erweiterte Anflage.

1912

Mündyen und Berlin

3. Gqweiger $\mathfrak{B} e r l a g$ (Althur Gellier). 


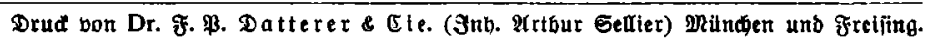

